7 Jacobsen BK, Thelle DS. The Tromso Heart Study: responders and non-responders to a health questionnaire, do they differ? Scand 7 Soc Med 1988;16:101-

8 Goldberg DP. The detection of psychiatric illness by questionnaire. London: Oxford University Press, 1972

9 Hansen V. Psychiatric service within primary care. Acta Psychiatr Scand 1987;76:121-8.

10 SPSS. Statistical package for the social sciences $X$. Users guide. 2nd ed. New York: McGraw-Hill, 1986

11 Jacobsen BK, Knutsen SF, Knutsen R. The Tromso Heart Study: comparison of information from a short food frequency questionnaire with a dietary history survey. Scand F Soc Med 1987;15:41-7.

12 Johnsen R, Jacobsen BK, Forde OH. Associations between symptoms of irritable colon and psychological and social conditions and lifestyle. BrMed f 1986;292:1633-5.

13 Johnsen R, Straume B, Forde OH. Peptic ulcer and non-ulcer dyspepsia-a disease and a disorder. Scand 7 Prim Health Care 1988;6:239-43.

14 Arnesen E, Forsdahl A. The Tromso Heart Study: coronary risk factors and their association with living conditions during childhood. $f$ Epidemiol Community Health 1985:39:210-4.
15 Jacobsen BK, Hansen V. Caffeine and health. BrMed f 1988;296:291.

6 Jacobsen BK, Hansen V. Mental problems and frequent use of analgesics. Lancet 1989;i:273.

17 Frederick T, Frerichs RR, Clark VA. Personal health habits and symptoms of depression at the community level. Prev Med 1988;17:173-82.

18 Kawakami N, Haratani T, Kaneko T, Koizumi A. Relationships between health practices and depressive mood among industrial workers. Fapanese Journal of Industrial Health 1987;29:55-63.

19 Parker DA, Parker ES, Harford TC, Farmer GC. Alcohol use and depression symptoms among employed men and women. Am 7 Public Health 1987;77:704-7.

20 Frerichs RR, Aneshensel CS, Clark VA, Yokopenic P. Smoking and depression: a community survey. Am F Public Health 1981;71:637-40.

21 Kaplan GA, Roberts RE, Camacho TC, Coyne JC. Psychosocial predictors of depression. Prospective evidence from the human population laboratory depression. Prospective evidence from the
studies. Am $\mathcal{F}$ Epidemiol 1987;125:206-20.

22 Aneshensel CS, Huba GJ. Depression, alcohol use, and smoking over one year: a four-wave longitudinal causal model. $\mathcal{F}$ Abnorm Psychol 1983;92:134-50.

(Accepted 4 May 1989)

\title{
Excess benign melanocytic naevi after chemotherapy for malignancy in childhood
}

\author{
Bronwyn R Hughes, W J Cunliffe, C C Bailey
}

\begin{abstract}
Objective-To see whether children who have had chemotherapy develop increased numbers of moles.

Design-Blind assessment of patients having chemotherapy and subsequent comparison with the first suitable patients matched for age and sex who were attending the clinic during the same period after having completed treatment. Controls were obtained the following year by taking the first suitable patients attending a routine dermatology outpatient clinic who matched the study groups for age and sex.
\end{abstract}

Setting-Referrals to a paediatric oncology clinic and a dermatology clinic at two city hospitals.

Patients-The group receiving chemotherapy comprised all 32 patients with acute lymphatic leukaemia, lymphoma, and rhabdomyosarcoma who were attending the paediatric oncology clinic on two mornings a week during October 1987 to March 1988. The group who had completed treatment comprised 32 patients who were attending for follow up during the same period and who matched the first group for age and sex. Thirty two other patients attending the dermatology outpatient clinic with unrelated skin conditions served as controls.

End point-Definite increase in numbers of moles on children after a course of chemotherapy.

Measurements and main results-Moles were counted by one observer on defined areas of the body and divided into those $<3 \mathrm{~mm}$ and $\geqslant 3 \mathrm{~mm}$ diameter. Patients receiving chemotherapy had a similar number of moles to the control group. By contrast patients who had completed chemotherapy had significant increases both in moles $<3 \mathrm{~mm}$ and $\geqslant 3$ $\mathrm{mm}$ and in the total number of moles. These patients were more likely to have moles on acral sites.

Conclusions-Children with substantially increased numbers of moles (benign melanocytic naevi) after successful chemotherapy for malignancy may have an increased risk of melanoma. They should be offered prolonged surveillance and cautioned about exposure to ultraviolet light.

\section{Introduction}

Patients who survive treatment that includes immunosuppression have an increased susceptiblity to cutaneous tumours and infections. ${ }^{12}$ There is no published information on the effects of benign tumours. During follow up in the paediatric oncology clinic in Leeds we noted that some children seemed to have developed an excess of moles after successful chemotherapy for leukaemia and lymphoma. As little is known about the aetiology of benign melanocytic naevi, we decided to study these children further. We aimed at assessing the cause of these moles and at learning more about the aetiology of benign melanocytic naevi.

\section{Patients and methods}

During October 1987 to March 1988 all patients attending for follow up in the paediatric oncology clinic on two mornings a week were interviewed and examined. They included patients receiving maintenance chemotherapy and those who had successfully completed chemotherapy. All patients were seen by one of us (BRH). Both dermatologists (BRH, WJC) saw the first 14 patients jointly and agreed on definition of the naevi and ensured standardisation of counts. Mole counts were performed on the children on arrival at the clinic without knowledge of the diagnosis and treatment, making that part of the study blind. The moles were counted on defined anatomical areasnamely, the face, anterior trunk, posterior trunk, upper and lower arms, upper and lower legs, palms, and soles. The moles were counted according to size and divided into those $\geqslant 3 \mathrm{~mm}$ and $<3 \mathrm{~mm}$ diameter. Only benign melanocytic naevi were included; in particular, all lesions present since birth and freckles were excluded.

The skin type was noted, as was the patient's race. Acute exposure to ultraviolet light was assessed by asking about time spent abroad-for example, on Mediterranean holidays. After the mole counts were completed disease, duration of treatment, and if applicable time since completing treatment were ascertained.

Controls were obtained from subjects attending the dermatology outpatient clinic for unrelated skin conditions. Comparisons were then made of the numbers of moles occurring among (a) normal controls, $(b)$ patients having treatment, and $(c)$ patients who had completed treatment. These patients were matched for sex, age (to within two years), and whenever possible race.

Analysis of the three groups was performed with a two way analysis of variance and the Newman-Keuls test used to determine the significance of differences 
among the groups. Logged values of mole counts were used to normalise the data.

\section{Results}

Patients who had completed chemotherapy had the most moles. They occurred particularly on the trunk (figure), but they also occurred on arms and legs and on both palms and soles. Some of the moles were macular, some were papular, and pigmentation and outline were variable. None was examined histologically. Table I gives the details of patients in the three groups and table II shows the diagnoses in the chemotherapy treatment groups. The patients with acute lymphatic leukaemia were given chemotherapy according to the regimens of the United Kingdom acute lymphoblastic leukaemia trial, which entail two or three years of chemotherapy and cranial irradiation. Those with lymphoma were treated with multiple chemotherapeutic agents and radiotherapy, and those treated for rhabdomyosarcoma received chemotherapy with multiple drugs. Those who had completed treatment had finished a mean of 28 months (range 3-70) before.

Table III shows the mean numbers of moles according to size in the three groups. Analysis of variance showed a highly significant difference among the three groups $(p<0.001)$. This was true when comparing total numbers of moles and also when counting moles $<3$ $\mathrm{mm}$ and $\geqslant 3 \mathrm{~mm}$. By using the Newman-Keuls test and a significance level of $5 \%$ a significant difference was found between the numbers of moles on patients after

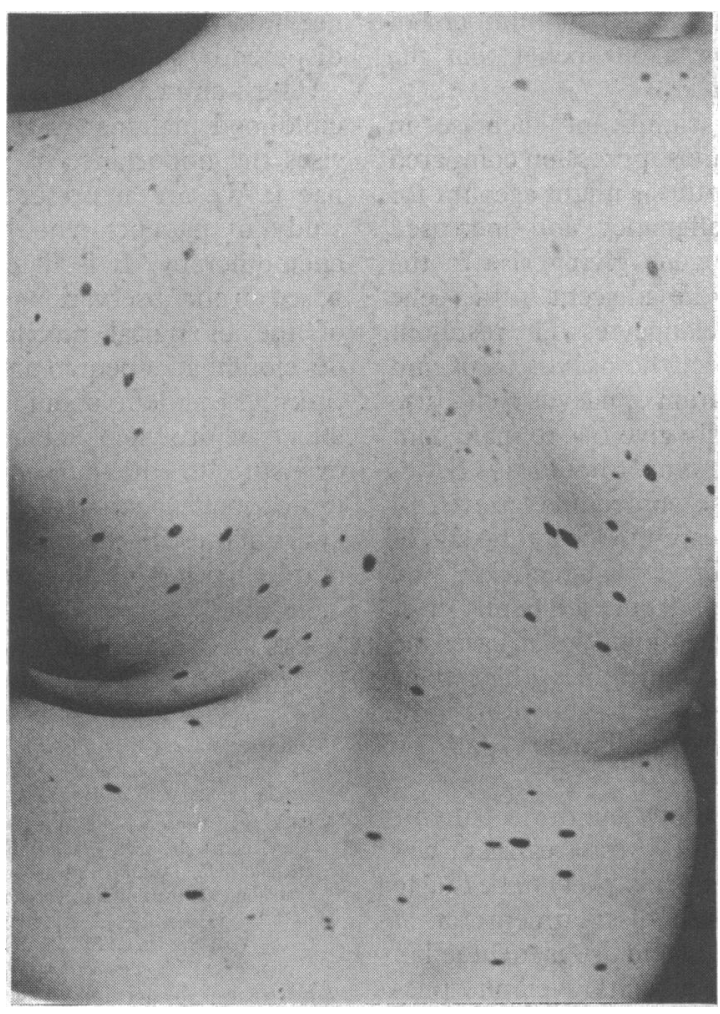

Moles on the back of a patient after chemotherapy

TABLE I-Details of patients in the three groups

\begin{tabular}{lccc}
\hline & $\begin{array}{c}\text { During } \\
\text { treatment }\end{array}$ & $\begin{array}{c}\text { After successful } \\
\text { treatment }\end{array}$ & Controls \\
\hline $\begin{array}{l}\text { No of patients } \\
\text { Mean age (years) (range) }\end{array}$ & 32 & 32 & 32 \\
Sex: & $9(4-15)$ & $10(4-17)$ & $10(4-16)$ \\
$\quad$ Boys & 20 & 20 & \\
$\quad$ Girls & 12 & 12 & 20 \\
$\begin{array}{l}\text { Race: } \\
\quad \text { White }\end{array}$ & 28 & 29 & 12 \\
$\quad$ Asian & 4 & 3 & 3 \\
$\begin{array}{l}\text { Mean time since completing } \\
\text { treatment(months) }\end{array}$ & & 28 & \\
& & & \\
\hline
\end{tabular}

TABLE II-Numbers of patients and their diagnoses in the two chemotherapy treatment groups

\begin{tabular}{lcccc}
\hline & $\begin{array}{c}\text { Acute } \\
\text { lymphatic } \\
\text { leukaemia }\end{array}$ & Lymphoma Rhabdomyosarcoma & Total \\
\hline $\begin{array}{l}\text { No during treatment } \\
\text { No after successful } \\
\text { treatment }\end{array}$ & 25 & 3 & 4 & 32 \\
\hline
\end{tabular}

TABLE III-Mean numbers of moles in each group according to size ( $95 \%$ confidence intervals in parentheses)

\begin{tabular}{lccc}
\hline Size of moles & $\begin{array}{c}\text { During } \\
\text { treatment }\end{array}$ & $\begin{array}{c}\text { After successful } \\
\text { treatment }\end{array}$ & Controls \\
\hline$<3 \mathrm{~mm}$ & $38 \cdot 3(16 \cdot 8$ to $59 \cdot 8)$ & $86 \cdot 7(59 \cdot 7 \text { to } 113 \cdot 7)^{\star}$ & $33 \cdot 0(24 \cdot 5$ to $41 \cdot 5)$ \\
$\geqslant 3 \mathrm{~mm}$ & $4 \cdot 8(2 \cdot 9$ to $6 \cdot 7)$ & $27 \cdot 0(16 \cdot 8 \text { to } 37 \cdot 2)^{\star}$ & $8 \cdot 8(5 \cdot 1$ to $12 \cdot 5)$ \\
\hline All & $42 \cdot 0(19 \cdot 2$ to $64 \cdot 8)$ & $114 \cdot 0(78 \cdot 3 \text { to } 149 \cdot 7)^{\star}$ & $41 \cdot 8(30 \cdot 0$ to $53 \cdot 68)$
\end{tabular}

${ }^{\star} \mathrm{p}<0.001$ Compared with other groups.

treatment compared with patients during treatment and controls.

Table IV gives the proportions of patients with moles on acral sites and the numbers of moles on the palms and soles of these patients. Larger proportions of patients both during treatment (16/32) and after treatment (13/32) had acral moles compared with controls (3/32). When analysing the numbers of moles on these sites with the Newman-Keuls test, however, those who had completed treatment had significantly higher numbers of moles compared with the other two groups $(p<0.05)$.

TABLE IV - Numbers of patients with moles on acral sites

\begin{tabular}{lccc}
\hline & $\begin{array}{c}\text { During } \\
\text { treatment }\end{array}$ & $\begin{array}{c}\text { After successful } \\
\text { treatment }\end{array}$ & Controls \\
\hline $\begin{array}{l}\text { No(\%) of patients with } \\
\text { acral moles }\end{array}$ & $16(50)$ & $13(41)$ & $3(9)$ \\
Mean No of moles(range) & $0 \cdot 8(0-6)$ & $3 \cdot 0(0-14)^{\star}$ & $0 \cdot 2(0-2)$ \\
\hline
\end{tabular}

$\star \mathrm{p}<0.05$ Compared with other groups.

There was no significant difference among the three groups in acute exposure to ultraviolet light or skin types.

\section{Discussion}

Barker and MacDonald reported a case of eruptive dysplastic naevus syndrome in a 20 year old man given immunosuppressive treatment after renal transplantation. ${ }^{3}$ This is the only previously reported case of increase in melanocytic lesions (excluding melanoma) after chemotherapy. Surveys of the prevalence of moles in normal populations have shown that the number of moles increases during childhood, reaches a peak in early adulthood, and then declines throughout life. ${ }^{47}$ The number of moles varies according to race. A few studies have looked at moles in non-white subjects, ${ }^{8}$ but none has assessed moles according to age and none has included Asian populations. MacKie et al have reported on the only study of white people in Britain that included children and adults. ${ }^{7}$ They studied naevi $\geqslant 3 \mathrm{~mm}$ diameter and found that the mean number of moles was 3 in children under 10 and 20 in people aged 10-19. Naevi were slightly more prevalent in male subjects. All but 10 of the 96 children in our study were white, and the numbers of moles both in the control group and in the group still receiving chemotherapy were comparable with the findings of MacKie et al.

Little is known about the biology of benign naevi. Race and heredity seem to be important, and in the dysplastic naevus syndrome inheritance has been described. ${ }^{9}$ We matched patients for race as far as possible, as this may affect the numbers of naevi. 
There was one extra Asian patient in the group of children who were still having treatment; this should have not affected the results, however, as we find that Asians have fewer moles than white people.

Hormonal factors play a part, as evidenced by the increase in moles at puberty and by reports of both darkening of moles and their increase during pregnancy. ${ }^{10}$ Moles may contain oestrogen and progesterone receptors, which would account for these changes. "The effects of exposure to ultraviolet light are not clear, studies having given conflicting results. ${ }^{12} 13$

There are reports of sudden increases in numbers of moles occurring spontaneously, ${ }^{14}$ during puberty ${ }^{15}$ and pregnancy, ${ }^{10}$ and after treatment with corticotrophin and cortisone ${ }^{16}$ Most of our patients were prepubertal, and the fact that they were matched for age and sex should have eliminated any bias. All but five of our patients were treated with prednisolone. This may have contributed to our findings, but whether these were due to immunosuppression or another mechanism is unknown.

We not only counted moles of $\geqslant 3 \mathrm{~mm}$ diameter as in the study by MacKie $e t a l$ but in addition we counted smaller moles, as we consider that children have a number of smaller, darkly pigmented lesions which are junctional naevi. We did not sample any of the lesions for biopsy, as none looked dysplastic and the patients were too young. There was no difference among the three groups in acute exposure to ultraviolet light or skin types. It would have been an advantage to assess our patients before chemotherapy, but this was not possible. Nevertheless, the increase in numbers of moles after treatment supports our belief that the observation may be important.

Our patients showed a significant increase in numbers of moles after immunosuppression compared with controls. A genetic hypothesis might account for the association between malignancy and increased numbers of moles. An oncogene giving rise to the malignant clone of cells may lie adjacent to the gene controlling proliferation of melanocytes. The resultant gene amplification might affect the naevus locus and give rise to increased proliferation of naevus cells. If so a further step might potentially give rise to malignant naevus cells, - that is, a melanoma. Should this be so, knowing the site of the gene controlling growth of naevus cells could lead to research to locate the site of oncogenes producing childhood malignancies. We were able to examine one parent from each family of 17 children who had completed treatment; in all cases the patients had larger numbers of moles than their relatives, suggesting that this was not a genetic association. We are adding to these preliminary data by studying a cohort of sibs.

The significant difference between those patients still having treatment and those whose treatment was completed suggests that this effect is likely to be due to immunosuppression as a result of treatment rather than the underlying disease. Certain drugs included in the cytotoxic regimens of these patients (cyclophosphamide, doxorubicin, and daunorubicin) are known to cause generalised hyperpigmentation, but to date there are no reports of these drugs giving rise to increased numbers of benign melanocytic naevi.

After chemotherapy for haematological malignancies patients have an increased risk of developing second tumours. Greene and Wilson found an excess of malignant melanoma in male patients in a large epidemiological survey of patients treated for leukaemia and Hodgkin's and non-Hodgkin's lymphomas. ${ }^{17}$ This excess did not persist in long term survivors. Most of the data from leukaemic patients relate to adults with chronic lymphatic leukaemia. The long term risks of developing second tumours after acute lymphatic leukaemia in childhood seems small. Tucker et al reported only four second cancers in 1530 long term survivors. ${ }^{18}$ Nevertheless, as new and more effective chemotherapy regimens evolve risks may change.

The increase in malignant melanoma is thought to be due to less efficient immune surveillance as a result of immunosuppressive effects on the immune system. ${ }^{19-21}$ Little is known about the long term effects of intensive courses of chemotherapy on the immune system. The lack of excess tumours in the long term-that is, 10 years after chemotherapy - may suggest a return of the immune system to normal. This would be in keeping with the observations of our patients - namely, that the moles seem to arise towards the end of or immediately after completion of chemotherapy. Long term studies are required to see whether the numbers of naevi continue to increase over the years subsequent to chemotherapy. Both our patients who had completed chemotherapy and those still having chemotherapy had increased numbers of acral moles, suggesting that this is the first site exposed to the immunosuppressive effect on the melanocytes. On analysing the numbers of acral moles, however, the significant difference lay between those who had completed treatment and the other two groups.

Having increased numbers of benign melanocytic naevi seems to be one of the strongest risk factors for the development of malignant melanoma, ${ }^{22} 23$ and so these children may be a group prone to that disease. Acral moles may also have an increased malignant potential, ${ }^{24}$ and so it is possibly also a matter for concern that out patients had an excess number of naevi on the palms and soles. This view, however, is disputed by some doctors. ${ }^{10}$

The numbers of children successfully treated for childhood malignancy are increasing, which emphasises the importance of prospective studies of these naevi. We are at present undertaking a prospective study of patients who have yet to complete their chemotherapy. It is likely that subsequent research based on our observations will add to our understanding of the biological mechanisms responsible for the development of benign melanocytic naevi. In the mean time these patients should be warned of the detrimental effects of ultraviolet light and advised to avoid excessive exposure to the sun and to apply adequate sun protection. Doctors concerned in their care should be aware of these findings and should include examination of the skin in the long term follow up of these patients.

1 Korander FC, Dehmel EM, Kahn G, Penn I. Cutaneous complications in immunosuppressed renal homograft recipients. FAMA 1974;229:419-24

2 Kinlen LJ, Sheil AGR, Peto J, Doll R. Collaborative United Kingdom Australasian study of cancer in patients treated with immunosuppressive drugs. Br Med f 1979;ii:1461-6.

3 Barker JNWN, MacDonald DM. Eruptive dysplastic naevi following renal transplantation. Clin Exp Dermatol 1988;13:123-5.

4 Pack GT, Lenson N, Gerber DM. Regional distribution of moles and melanoma. Arch Surg 1952;65:862-70.

5 Nicholls EM. Development and elimination of pigmented moles, and the anatomical distribution of primary malignant melanoma. Cancer 1973; $32: 191-5$.

6 Cooke KR, Spears GFS, Skegg DCG. Frequency of moles in a defined population. $\mathcal{F}$ Epidemiol Community Health 1985;39:48-52.

7 MacKie RM, English J, Aitchison TC, Fitzsimmons CP, Wilson PD. The number and distribution of benign pigmented moles (melanocytic naevi) in a healthy British population. Br f Dermatol 1985;113:167-74.

8 Pack GT, Davis J, Oppenheim A. The relation of race and complexion to the incidence of moles and melanomas. Ann NY Acad Sci 1963;100:719-42.

9 Clark WH, Reimer RR, Green M, Ainsworth AM, Mastrangelo MJ. Origin of familial malignant melanomas from heritable melanocytic lesions. "The B-K mole syndrome'. Arch Dermatol 1978;114:732-8.

10 Mackie RM. Melanocytic naevi. In: Rook A, Wilkinson DS, Ebling FJG, Champion RH, Burton JL, eds. Textbook of dermatology. th ed. Oxford: Blackwell Scientific, 1986:181.

11 Ellis DL, Wheeland RG. Increased nevus estrogen and progesterone ligand binding related to oral contraceptives or pregnancy. $\mathcal{J} \mathrm{Am}$ Acad Dermatol 1986;14:25-31.

12 Armstrong BK, de Kerk NH, Holman DJ. Etiology of common acquired melanocytic nevi: constitutional variables, sun exposure and diet. $尹$ JNCI melanocytic nevi:
$1986 ; 77: 329-35$.

13 Rampen FHJ, Fleuren BAM, de Boo TM, Lemmers WAJG. Prevalence of common 'acquired' nevocytic nevi and dysplastic nevi is not related to ultraviolet exposure. F Am Acad Dermatol 1988;18:679-83

14 Eady RAJ, Gilkes JJH, Jones EW. Eruptive naevi: report of two cases, with 
enzyme histochemical, light and electron microscopical findings. $\mathrm{Br} f$ Dermatol 1977;97:267-78.

15 Coskey RJ Eruptive nevi. Arch Dermatol 1975;111:1658.

16 Goldman L, Richfield DF. Effect of corticotrophin and cortisone on the development and progress of pigmented nevi. FAMA 1951;143:941-3.

17 Greene $\mathrm{MH}$, Wilson J. Second cancer following lymphatic and hematopoietic cancers in Connecticut, 1935-82. NCI Monogr 1985;68:191-219.

18 Tucker MA, Meadows AT, Boice JD Jr, et al. Cancer risk following treatment of childhood cancer. In: Boice JD Jr, Fraumeni JF Jr, eds. Radiation carcinogenesis: epidemiology and biological significance. New York: Raven Press, 1984:211-24.

19 Greene $\mathrm{MH}$, Hoover RN, Fraumeni JF Jr. Subsequent cancer in patients with

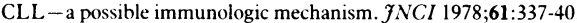

20 Greene MH, Young TI, Clark WH Jr. Malignant melanoma in renal transplant recipients. Lancet 1981;i:1196-8.

21 Tucker MA, Misfeldt D, Coleman CN, et al. Cutaneous malignant melanom following Hodgkin's disease. Ann Intern Med 1985;102:37-41.

22 Swerdlow AJ, English J, MacKie RM, et al. Benign melanocytic naevi as a risk factor for malignant melanoma. Br Med f 1986;292:1555-9.

23 Green A, Maclennan R, Siskind V. Common acquired nevi and the risk of malignant melanoma. Int f Cancer 1985;35:297-300.

24 Allen AC. A reorientation on the histogenesis and clinical significance of cutaneous nevi and melanomas. Cancer 1949;28-41.

(Accepted 12 April 1989)

\title{
Is excessive running predictive of degenerative hip disease? Controlled study of former elite athletes
}

\author{
Bernard Marti, Michael Knobloch, Alois Tschopp, Armin Jucker, Hans Howald
}

Institute of Social and Preventive Medicine, University of Zurich, Zurich, Switzerland Bernard Marti, MD, research fellow

Michael Knobloch, MD, assistant researcher

Alois Tschopp, Msocsc, research fellow

Department of Radiology, Cantonal Hospital, Schaffhausen, Switzerland Armin Jucker, MD, head of department

Research Institute, Swiss School for Physical

Education and Sports, Magglingen, Switzerland Hans Howald, MD, head

Correspondence to: Dr Bernard Marti, Institute of Social and Preventive Medicine, University of Zurich, CH-8006 Zurich, Switzerland.

BrMed J 1989;299:91-3
Abstract

Objective-To determine the effects of regular long distance running on the state of the hips in later life.

Design-Retrospective study of a cohort of elite athletes and a group of normal, healthy, untrained controls examined 15 years after initial testing.

Setting-Research project at school for physical education and sports.

Subjects -27 Former long distance runners (mean age 42), nine former bobsleigh riders (mean age 42), and 23 normal, healthy, untrained men (mean age 35) who had been examined in 1973 and who agreed to re-examination in 1988.

Main outcome measure-Radiological evidence of degenerative hip disease in 1988.

Results-Physiological and exercise characteristics of all subjects had been recorded in 1973, and in 1988 these measurements were repeated together with radiological examination of the hips. An additive radiological index of hip disease based on grades of subchondral sclerosis, osteophyte formation, and joint space narrowing was significantly increased among runners as compared with bobsleigh riders and untrained controls. After adjustment for age the significant effect of type of sports activity remained $(p=0.032)$. In multivariate analyses age and milage run in $1973(97 \mathrm{~km} /$ week) emerged as independent, significant, and positive predictors of radiological signs of degenerative hip disease in $1988(p=0.017$ and $p=0.024$ respectively $)$. Among runners alone running pace in 1973 rather than milage run was the stronger predictor of subsequent degenerative hip disease. The milage run in 1988 was not particularly predictive of the radiological index, but endurance in 1988 was inversely related to degenerative hip disease seen radiologically.

Conclusion-Long term, high intensity, high milage running should not be dismissed as a potential risk factor for premature osteoarthritis of the hip.

\section{Introduction}

Regular exercise brings several possible health benefits - for example, improved fitness, decreased cardiovascular disease, increased longevity, and emotional wellbeing. ${ }^{1}$ Nevertheless, little information exists about the long term consequences, if any, of exercise on the musculoskeletal system. It has been hypothesised that the repetitive impulse loading of an activity such as habitual running might accelerate the development of degenerative disease in the weight bearing joints. ${ }^{2}$ Indeed, osteoarthritis of the hip was found to be more common in retired football players who had played regularly for more than two decades. On the other hand, a retrospective study of elite athletes found a decreased prevalence of osteoarthritis of the hip among former Finnish champion runners, ${ }^{4}$ and two recent cross sectional investigations failed to identify any significant association between habitual running and premature degenerative disease of the hip. ${ }^{56}$ Recent reviews have therefore concluded that at present there is no convincing evidence that running accelerates the development of osteoarthritis in weight bearing joints. ${ }^{78} \mathrm{We}$ report a controlled retrospective study of the association between running and subsequent degenerative hip disease in a cohort of former elite athletes.

\section{Subjects and methods}

The study sample consisted of the complete Swiss national teams in long distance running (track and field and orienteering) and bobsleigh who had taken part in an exercise test and physical examination at the Swiss School for Physical Education and Sports in 1973. The control group consisted of healthy, untrained men who had volunteered for a randomised training study in 1973 and who had been subjected to the same tests and physical examination protocol as the elite athletes. Of the 27 long distance runners approached, all agreed to take part in the same exercise test and physical examination 15 years later-that is, in 1988; of the 12 bobsleigh riders approached, nine agreed to participate; and of the 26 control subjects approached, 23 agreed to participate (one had died). The total study sample therefore comprised 59 men ( $92 \%$ of those eligible).

Subjects completed a detailed questionnaire on exercise habits, history of sports related injuries, and medical history. In 1988 the subjects also had a rheumatological examination of the legs and an $x$ ray examination of the hips (supine anteroposterior view of pelvis). All radiographs were scored "blind" by an experienced radiologist not associated with the study. Each radiograph was scored for joint space narrowing, subchondral sclerosis, and osteophyte formation. On the films the joint space, expressed as the distance between the ossified surfaces and representing the thickness of the joint cartilage, was measured cranially. Joint space narrowing was classified as grade zero if cartilage thickness was $\geqslant 3 \mathrm{~mm}$, grade 1 if $<3 \mathrm{~mm}$, grade 2 if $<2.5 \mathrm{~mm}$, and grade 3 if $<2 \mathrm{~mm}$. Subchondral sclerosis and osteophyte formation were scored zero (absent) to 3 (excessive) according to standard criteria. ${ }^{9}$ A simple radiological index of degenerative hip disease was then computed by summing the classifications of joint space narrowing, sclerosis, and 